\title{
Spatial-temporal patterns of vegetation dynamics and their relationships to climate variations in Qinghai Lake Basin using MODIS time-series data
}

\author{
GUO Wei ${ }^{1}$, NI Xiangnan ${ }^{1}$, JING Duanyang ${ }^{1},{ }^{*}$ LI Shuheng ${ }^{2}$ \\ 1. School of Human Settlements and Civil Engineering, Xi'an Jiaotong University, Xi'an 710049, China; \\ 2. School of Urban and Resources Sciences, Northwest University, Xi'an 710032, China
}

\begin{abstract}
Global warming has led to significant vegetation changes in recent years. It is necessary to investigate the effects of climatic variations (temperature and precipitation) on vegetation changes for a better understanding of acclimation to climatic change. In this paper, we focused on the integration and application of multi-methods and spatial analysis techniques in GIS to study the spatio-temporal variation of vegetation dynamics and to explore the vegetation change mechanism. The correlations between $\mathrm{EVI}$ and climate factors at different time scales were calculated for each pixel including monthly, seasonal and annual scales respectively in Qinghai Lake Basin from the year of 2001 to 2012. The primary objectives of this study are to reveal when, where and why the vegetation change so as to support better understanding of terrestrial response to global change as well as the useful information and techniques for wise regional ecosystem management practices. The main conclusions are as follows: (1) Overall vegetation EVI in the region increased $6 \%$ during recent 12 years. The $E V I$ value in growing seasons (i.e. spring and summer) exhibited very significant improving trend, accounted for $12.8 \%$ and $9.3 \%$ respectively. The spatial pattern of EVI showed obvious spatial heterogeneity which was consistent with hydrothermal condition. In general, the vegetation coverage improved in most parts of the area since nearly $78 \%$ pixel of the whole basin showed increasing trend, while degraded slightly in a small part of the area only. (2) The EVI change was positively correlated with average temperature and precipitation. Generally speaking, in Qinghai Lake Basin, precipitation was the dominant driving factor for vegetation growth; however, at different time scale its weight to vegetation has differences. (3) Based on geo-statistical analysis, the autumn precipitation has a strong correlation with the next spring EVI values in the whole region. This findings explore the autumn precipitation is an important indicator, and then, limits the plant growth of next spring.
\end{abstract}

Keywords: Qinghai Lake Basin; EVI; precipitation; temperature; correlation analysis

Received: 2013-10-08 Accepted: 2014-07-10

Foundation: National Science \& Technology Support Program, No.2012BAH31B03; National Natural Science Foundation of China, No.41301007; No.40901101; The Fundamental Research Funds for the Central Universities, No.xjj2013079

Author: Guo Wei, PhD, specialized in physical geography. E-mail: williamguo@xjtu.edu.cn

*Corresponding author: Li Shuheng, PhD, E-mail: lish@nwu.edu.cn 


\section{Introduction}

Global climate change and its impact on the terrestrial ecosystems have caused public concern over the last several decades (Gaston, 2000; Cramer et al., 2001; Theurillat and Guisan, 2001). Increased attention has been paid to the dynamic rules of vegetation growth and its response to climate changes at regional, continental and global scales as vegetation provides a base for all living beings and plays an essential role in affecting global climate change (Jackson et al., 2008; Anderson et al., 2010; Verbesselt et al., 2010). The Qinghai-Tibet Plateau is a pilot region of climatic fluctuation which is extremely sensitive to global climate change (Feng et al., 1998). Qinghai Lake, located in the northeast of the Qinghai-Tibet Plateau, is the largest inland saltwater lake in China. Owing to its high altitude, closed catchment, and low-intensity human activities, the Qinghai Lake Basin (QLB) is, to some extent, an ideal location to directly study the environmental effects of climate change.

Assessing and monitoring the state of the earth surface vegetation is a key requirement for global change research. With the development of remote sensing technology, remotely sensed data have been increasingly widely used to monitor vegetation change, allowing us to update maps more frequently and on a near real-time basis (Huete et al., 2002; Guillevic et al., 2002; White et al., 2005; Sims et al., 2006; Frolking et al., 2009). Recent development of space-borne sensors (e.g., Moderate Resolution Imaging Spectroradiometer, MODIS) has systematically generated ecological indicators available at regional scales, and can provide geospatial products that reveal continuous patterns in both space and time often crucial to uncovering cause and consequence (Justice et al., 1998). MODIS time series dataset can now be acquired at varying spatial $(250 \mathrm{~m}$ to $1 \mathrm{~km})$ and temporal (daily to annual) resolutions globally to track environmental impacts such as land use, disturbance, and climate change.

Quantifying the spatio-temporal pattern of vegetation change at the regional scale is critical in providing a theoretical basis for evaluating interaction between climate change and terrestrial ecosystems. At present, activity of vegetation systems is commonly quantified using remotely sensed vegetation indices (VI). Vegetation index is the indicative factor of vegetation density and growth status, it has positive correlation with vegetation coverage, and, to a certain extent, variations of vegetation index can reveal the changes of vegetation coverage (Huete et al., 2002). Therefore, researchers have made great efforts on monitoring global vegetation coverage changes by vegetation indices since the 1980s. There are two types of MODIS vegetation indices, the Normalized Difference Vegetation Index (NDVI) and the Enhance Vegetation Index (EVI) (Justice et al., 1998). EVI has been designed to improve upon the quality of NDVI product, it corrects for some distortions in the reflected light caused by the particles in the air as well as the ground cover below the vegetation $(\mathrm{Hu}-$ ete et al., 1994; Gao et al., 2000).

Temperature and precipitation are key drivers of ecosystem processes (Cramer et al., 2001; Piao et al., 2004; Fay et al., 2008). To further study the relationship between vegetation and climate and to get the spatial variation will boost the research on forecasting of growth status. With the influence of complicated topography, the change of vegetation in the QLB is typical and representative in the Qinghai-Tibet high altitude region, which is indispensable for the research about the global change and the response to the fragile region. Some studies 
have been done in this area to investigate vegetation change and its response to climate factors, but few made detailed analysis at pixel level. Moreover, the time lag effect of vegetation dynamics requires further investigation (Chen et al., 2007; Xu et al., 2008). Therefore, the primary objectives of this paper are to explore when, where and why the vegetation changed in the QLB from 2001 to 2012 by using the time series of MODIS-EVI data and meteorological data. The major research contents included the spatio-temporal change characteristics of EVI in the QLB, and the relationship between EVI and climate variables so as to explore the response mechanism of vegetation to the climatic variations (temperature and precipitation) at different spatial and temporal scales. The study will also offer scientific basis for the eco-environmental protection in the QLB and response study on fragile ecosystems to global climate change.

\section{Study area}

Qinghai Lake, on the northeastern margin of the Qinghai-Tibet Plateau situated at the transition from the arid to the semi-arid climate zones, is China's largest closed-basin lake, and is of considerable interest in the context of research on the Asian climate and environmental change.

The drainage area of the Qinghai Lake is approximately $29,600 \mathrm{~km}^{2}$, and the lake area is about $4,300 \mathrm{~km}^{2}$. The whole area extends from $36^{\circ} 15^{\prime} \mathrm{N}$ to $38^{\circ} 20^{\prime} \mathrm{N}$ and $97^{\circ} 50^{\prime} \mathrm{E}$ to $101^{\circ} 20^{\prime} \mathrm{E}$, and the average altitude ranges from $3194 \mathrm{~m}$ to $5174 \mathrm{~m}$ (Figure 1). The climate here, in winter, is controlled by Siberian high and Mongolian high and it is very cold and arid with very little rain and more strong winds. In summer, the climate is dominated by East-Asian monsoon and it is warm and moist. The average annual precipitation of the Qinghai Lake is approximately $350 \mathrm{~mm}$ based on the recent 50-year record. The Qinghai Lake is also very important water and wetland conservation area of western China included in the Ramsar Convention List of Wetlands of International Importance, which is extremely sensitive to ecological changes and it is also an area with abundant biodiversity in high altitude region.

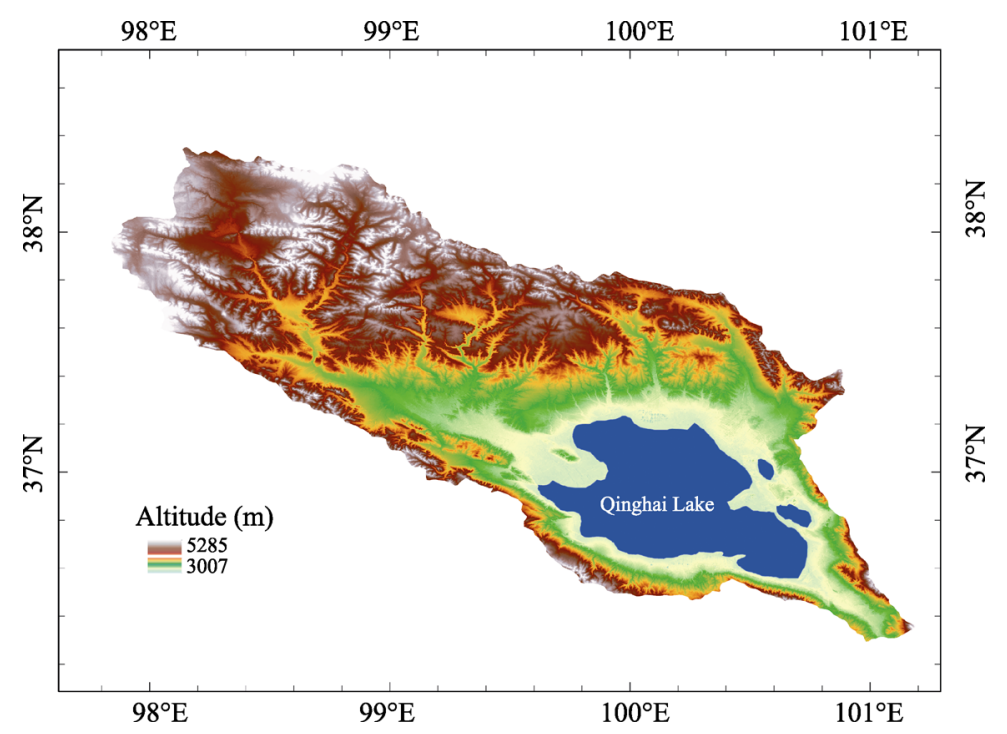

Figure 1 Map of the Qinghai Lake Basin 
In recent years, grassland degradation, desertification, and soil erosion were aggravating and wetlands of lake and river area were decreasing caused by global climate change and unreasonable resource development, indicating the gradual ecological deteriorating trend of the lake basin.

\section{Materials and methods}

\subsection{Dataset and preprocessing}

\section{(1) MODIS-EVI dataset}

After the launch of the two MODIS sensors on Terra (satellite) and Aqua (satellite), EVI data was provided since 2000 as a standard product by NASA and the EVI index became extremely popular due to its ability to eliminate background and atmosphere noises, as well as its non-saturation in high biomass regions while NDVI asymptotically saturates in high biomass regions (Huete et al., 2002). EVI is computed following this equation (Huete et al., 1994):

$$
\mathrm{EVI}=G \times \frac{(N I R-R E D)}{(N I R+C 1 \times R E D-C 2 \times B L U E+L)}
$$

where NIR/RED/BLUE are atmospherically-corrected or partially atmospheric corrected (Rayleigh and ozone absorption) surface reflectance, $L$ is the canopy background adjustment that addresses non-linear, differential NIR and red radiant transfer through a canopy, and $C 1$ and $C 2$ are the coefficients of the aerosol resistance term, which uses the blue band to correct aerosol influences in the red band. The coefficients adopted in the MODIS-EVI algorithm are; $L=1, C 1=6, C 2=7.5$, and $G$ (gain factor) $=2.5$ (Huete et al., 1994).

In this study, EVI time-series dataset was downloaded from EOS data gateway during 2001 to 2012. We selected the MODIS-derived 16-day composite vegetation indices (MOD13A1) of atmospherically-corrected maximal values at a $500 \mathrm{~m}$ resolution. These data were reprojected to Albers equal area projection and WGS84 datum from the original projection using the MODIS reprojection tool (MRT). The nearest neighbor resampling approach was employed. To reduce the image noises from atmospheric clouds, particles, shadows, etc., the Savitzky-Golay (S-G) filters are generally used for smoothing EVI time-series data (Chen et al., 2004).

(2) Meteorological data

Climate data including temperature and precipitation on different temporal scale were downloaded from China Meteorological Data Sharing Service System (http:/cdc.cma. gov.cn). The data from 7 climate stations in Qinghai Lake Basin was interpolated through the Kriging method to produce raster images with the same temporal and spatial resolution of the MODIS-EVI remote-sensing images.

(3) Maximum value composite method

The universal Maximum Value Composite (MVC) method was used to obtain monthly and annual EVI data based on 16 day composites, and to remove the noise caused by cloud, air, solar azimuth angle, and so on. The specific formula is as follows.

$$
E V I_{i}=\operatorname{Max}\left(E V I_{i j}\right)
$$

where $E V I_{i}$ is the EVI data of month $i$ or year $i$, and $E V I_{i j}$ is the EVI data of the $j$ th 16-day or 
month $j$ in month $i$ or year $i$.

\subsection{Trend analysis of EVI}

Simple linear regression analysis was used to simulate the trend of EVI from 2001 to 2012. The following simple linear regression analysis model was applied to each grid:

$$
\text { Slope }=\frac{n \times \sum_{i=1}^{n} E V I_{i}-\sum_{i=1}^{n} i \sum_{i=1}^{n} E V I_{i}}{n \times \sum_{i=1}^{n} i^{2}-\left(\sum_{i=1}^{n} i\right)^{2}}
$$

where $n$ is the number of studied years; $E V I_{i}$ is the maximum monthly $E V I$ of year $i$; Slope $>0$ means the changing tendency of vegetation coverage among $n$ years is increasing, on the contrary, it may decrease (Xu, 2002).

\subsection{Correlation analysis of EVI and climate factors}

The Pearson correlation coefficient is a measure of the linear correlation (dependence) between two variables $X$ and $Y$, giving a value between +1 and -1 inclusive, where 1 is total positive correlation, 0 is no correlation, and -1 is negative correlation. It is widely used in the sciences as a measure of the degree of linear dependence between two variables. This study uses Pearson correlation coefficient to measure the linear correlation among the temperature, precipitation and vegetation indexes in order to find the driving forces of vegetation change. The formula of Pearson correlation is as follows:

$$
r_{x y}=\frac{\sum_{i=1}^{n}\left(x_{i}-\bar{x}\right)\left(y_{i}-\bar{y}\right)}{\sqrt{\sum_{i=1}^{n}\left(x_{i}-\bar{x}\right)^{2} \sum_{i=1}^{n}\left(y_{i}-\bar{y}\right)^{2}}}
$$

where $r_{x y}$ is the simple correlation coefficient of variables $x$ and $y ; x_{i}$ is the vegetation index of the $i$ th year/month; $y_{i}$ is the temperature or precipitation of the $i$ th year/month; $\bar{x}$ is the average vegetation index for all years/month; $\bar{y}$ is the average temperature or precipitation for all years/month (Xu, 2002; Mu et al., 2013).

\section{Results and analyses}

\subsection{Spatio-temporal pattern of EVI value}

Quantifying the spatio-temporal pattern of vegetation change at the regional scale is critical in providing a theoretical basis for evaluating interaction between climate change and terrestrial ecosystems.

\subsubsection{Temporal changes of regional EVI}

In order to explore the natural fluctuation range of EVI, we calculated the linear regression coefficients of annual mean EVI value. Change curve and trend line of annual mean EVI in the QLB from 2001 to 2012 were calculated respectively (Figure 2). Change curve fluctuates periodically between 3 and 4 years. Trend line could filter the effects of short-term fluctuation in climate on vegetation cover and reflect integrated effect of environmental change on vegetation dynamics. Annual mean EVI of the whole basin was 0.18 . Overall vegetation 
EVI value was increased 6\% from 2001 to 2012, and the highest annual mean EVI occurred in 2005 while the lowest EVI in 2001.

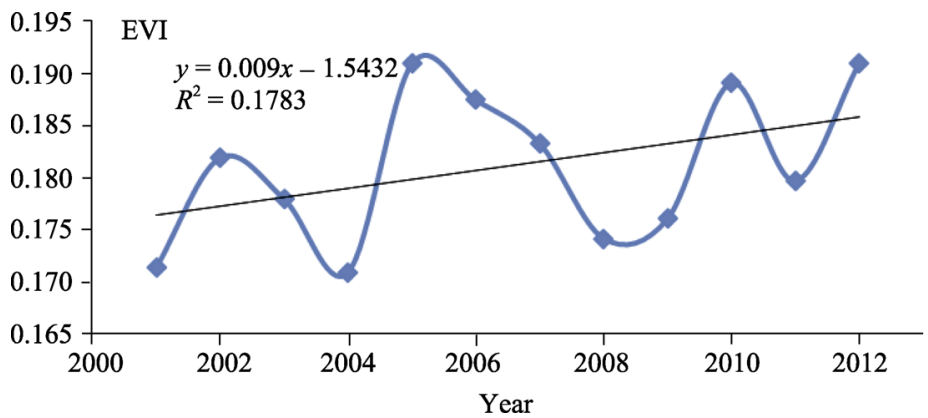

Figure 2 Variation of annual EVI of the Qinghai Lake Basin during 2001 to 2012

Since seasonal climate changes will bring various influences on vegetation growth, we further compared the seasonal change tendency of EVI for recent 12 years. The linear trend line in Figure 3a displays the EVI in spring increased very significantly at a rate of about 1\% per year. This was hypothesized to reflect a faster spring temperature rise in Tibet Plateau (Piao et al., 2011). Grasses turned green and began to grow in April, and the impacts of temperature on grass growth was obvious. Therefore, the increase of EVI in spring might be due to an advanced growing season caused by climatic warming. In addition, the linear trend line of EVI change in summer shows an obvious increase of about $0.8 \%$ per year (Figure $3 b$ ). This phenomenon revealed the phonology of steppe grassland in the QLB had changed including the date of grass turning green advanced and the length of growing season increased during the study period. It also reflected the feedback mechanisms of vegetation to global
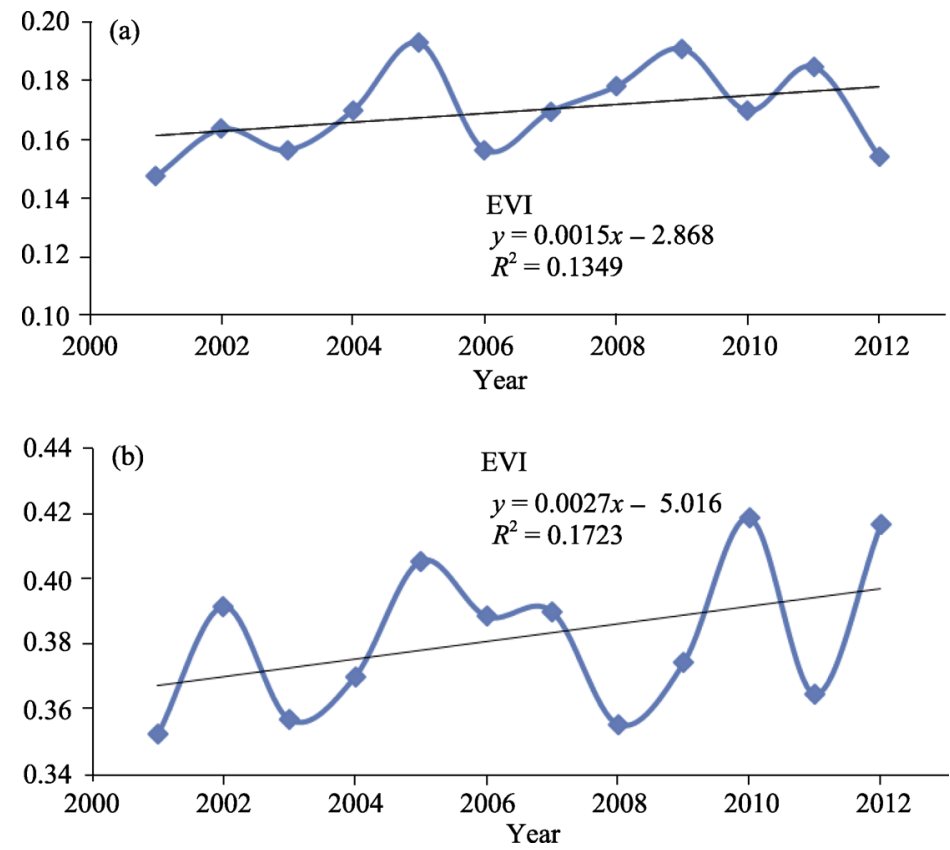

Figure 3 EVI change tendency in spring (a) and summer (b) from 2001 to 2012 
warming in the high-cold mountain area of northern Hemisphere, characterized by both the advanced growing season and accelerated vegetation activity (Zhou et al., 2001; Nemani et al., 2003; Piao et al., 2007).

\subsubsection{Spatial patterns of regional EVI}

The average annual EVI at pixel spatial scale from 2001 to 2012 was calculated to depict the spatial patterns of vegetation coverage (Figure 4). It shows that the mean EVI values decreased from southeast to northwest, being consistent with hydrothermal conditions. In the eastern and central parts of the basin, EVI reaches the highest, but in the western and northern parts, it is very low. The average annual EVI value from 2001 to 2012 was 0.18 , with definite spatial differences among the whole basin. EVI with value over 0.2 was mainly distributed in the central part of north Qinghai Lake which had the best pasture in Qinghai Province. Locations with the lowest EVI were mainly distributed in the northwestern mountain area and the Qinghai Lake shores, being af-

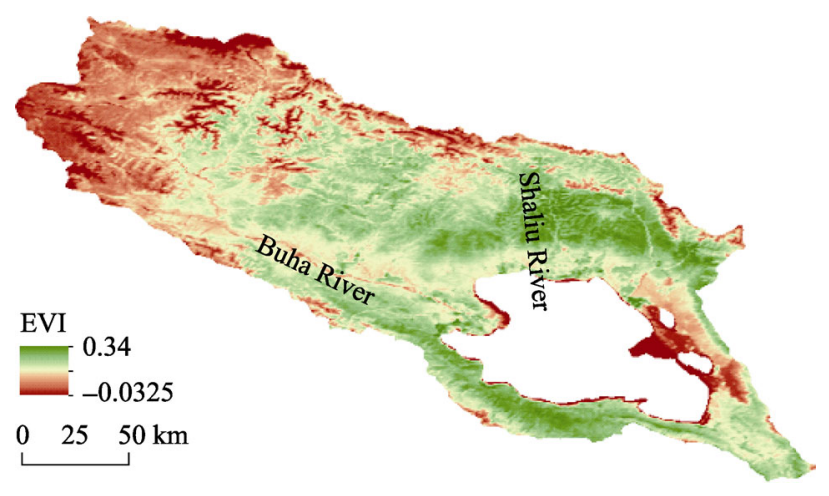

Figure 4 Spatial pattern of annual mean EVI from 2001 to 2012 fected seriously by sand desertification and soil erosion.

\subsubsection{Variations of EVI at pixel's scale}

Overall, the changing trend of annual vegetation EVI in the QLB is improving because nearly $78 \%$ of pixels show increasing trend. Spatially, these pixels mainly spread over south Qinghai Lake and the river banks of Buha. Areas with degrading trend of vegetation coverage are much more sparse, accounting for only $22 \%$ of the whole basin; moreover, most of these pixels haven't passed the test of 95\% significance level. Spatially, these pixels dispersed around the Qinghai Lake shores, and river mouths of Shaliu and other rivers located north of the Qinghai Lake. In addition, they are distributed in some parts of western mountain area (Figure 5).

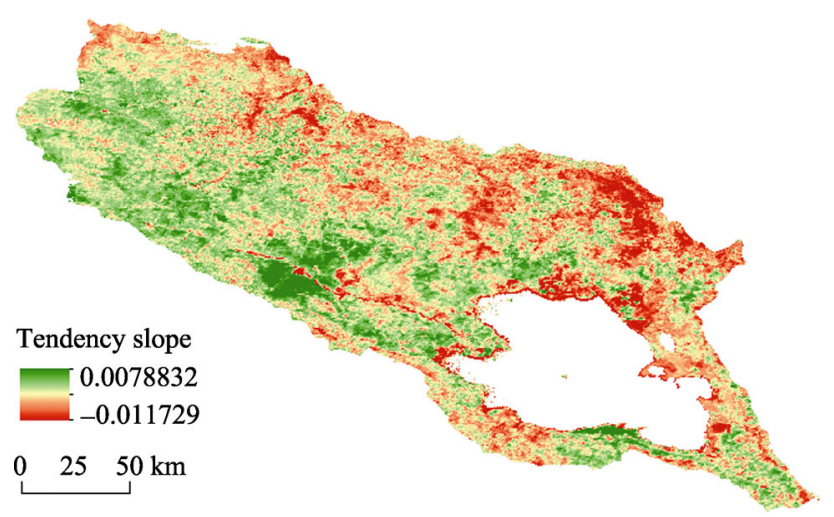

Figure 5 Spatial pattern of EVI change tendency

\subsection{Correlation of vegetation coverage and climate factors}

Air temperature and precipitation had been identified as major climate factors influencing the vegetation coverage. Comparison of the regional EVI value and major climate factors time series would indicate the QLB vegetation responses to fluctuation in air temperature and precipitation. Since annual and seasonal climate 
changes brought various influences on vegetation growth and ecological environment, the relationships between climate factors and EVI were analyzed upon different time scale including annual, seasonal, and monthly. Also, lag effects of vegetation dynamics were revealed based on mathematical statistics.

\subsubsection{The relationship between inter-annual EVI and climate factors}

In order to study the effect of climate factors on vegetation, we calculated the correlation between annual mean EVI and climate factors including the annual total precipitation and average mean temperature. On inter-annual time scale, the correlation coefficient of EVI value and precipitation in the whole region was 0.23 , while that of EVI and temperature was 0.098 . The area percentage of the regions where vegetation coverage showed a positive correlation with precipitation was $77.44 \%(22.26 \%, P<0.05 ; 13.26 \%, P<0.01)$. The area percentage of the regions where vegetation coverage showed a positive correlation with temperature was $64.12 \%(6.83 \%, P<0.05 ; 3.34 \%, P<0.01)$. It was implied that, in the QLB, the correlation with EVI was stronger for precipitation than that for temperature on inter-annual time scale.

In most parts of the eastern and central QLB, the correlation between annual mean EVI and annual effective precipitation is rather strong which indicated that the growth of meadow and meadow grassland mainly distributed in regions strongly depends on precipitation. Vegetation responses depend strongly on the plant communities, and we base our investigation on previous studies that have shown strong relations between precipitation and vegetation in other arid and semiarid areas (Li et al., 2004; Wang et al., 2003; Chamaille et al., 2006; Wang et al., 2010; Zhang et al., 2011; Mu et al., 2012).

Also, Figure 6 illustrates that the coexistence of positive and negative correlations between vegetation coverage and climate factors in the QLB would attribute to the different abilities of absorbing soil water for different vegetation types, which caused different response to the combined effects of water and heat.

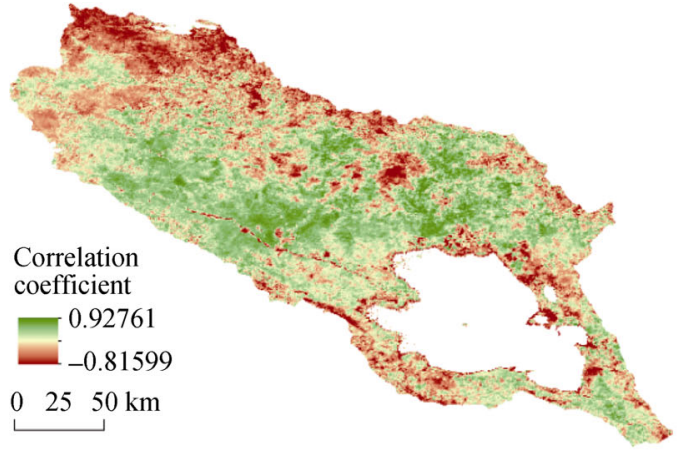

(a)

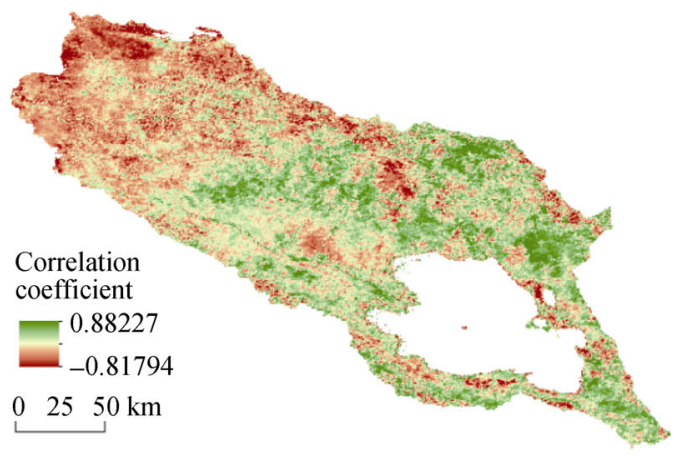

(b)

Figure 6 Correlations between annual EVI and climate factors in the Qinghai Lake Basin during 2001-2012 (a. with annual precipitation; $b$. with annual mean temperature)

\subsubsection{The relationship between EVI and climate factors in growing season}

In the QLB, temperature and precipitation changed drastically month-by-month within a year, and the temperature accorded very well with the precipitation (Figure 7). In the whole 
basin, the rainy season may last from the end of April to the end of September, but most of precipitation is concentrated in July and August. The growing season is in accord well with the rainy season. Therefore, we focus on the relationship of vegetation coverage and climate factors during growing season from May to September.

The EVI value was correlated with

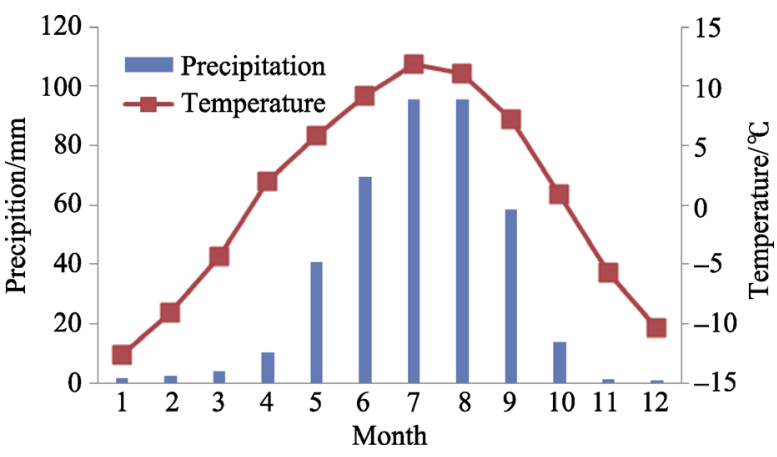

Figure 7 Monthly climatic factors variation pattern precipitation and temperature during growing season, accounting for 0.27 and 0.28 of the whole region, respectively. Here, temperature exerted equivalent effects as precipitation on vegetation coverage across the region. Therefore, vegetation growth with a year primarily relied upon the combined effects of water and heat rather than a single factor. Only when the two factors were both at the suitable level, can the plant begin to grow and can vegetation coverage show linear correlation with the climate factors. In addition, precipitation in most parts of the QLB increased during the grass growth season from May to September. The overall climate suitability of grassland vegetation also increased. Mao (2008) showed that humidity had an increasing trend in most parts of the Tibetan Plateau from 1961 to 2006. Hence, climate change tended to increase temperature and humidity in the QLB during the grass growth season, which is favorable to plant growth.

\subsubsection{The relationship between monthly EVI and climate factors}

The relationship between monthly vegetation EVI value and climate factors in the same month in the QLB was shown in Figure 8. Totally, the correlation between vegetation EVI index and precipitation was much stronger on inter-monthly time scales $(0.87)$ than that inter-annual time scales (0.23) (Figure 8a). Also, the correlation between EVI and temperature was much stronger on inter-monthly time scales $(0.77)$ than that on inter-annual time scale $(0.098)$ (Figure $8 \mathrm{~b}$ ). The area percentage of the region where vegetation coverage showed a positive correlation with precipitation was $99.77 \%$, furthermore, more than $93.92 \%$ pixel passed the test at significance level of $99 \%$. The area percentage of the regions where vegetation coverage showed a positive correlation with temperature was $99.73 \%$ $(88.28 \%, \mathrm{P}<0.01)$. Spatially, vegetation coverage in alpine meadow around the Qinghai Lake appeared to be influenced by both precipitation and temperature, and correlation coefficients varied from about 0.72 to 0.96 . However, there was a negative correlation between EVI and climate factors only in the northwestern alpine regions and the desert around the Qinghai Lake shore. The vegetation coverage there was sparse, and influenced by strong effect of land surface albedo of alpine snow and desert, which might lead to a weak even negative correlation with both precipitation and temperature. The significant correlation between monthly variation of EVI and climatic factors represent temporal rhythm controls of temperature and precipitation on vegetation growth, and to some extent, it might be the strategy for alpine vegetation in the QLB. 


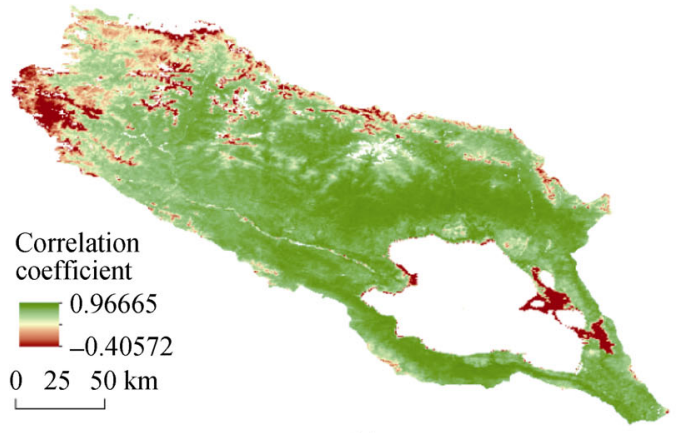

(a)

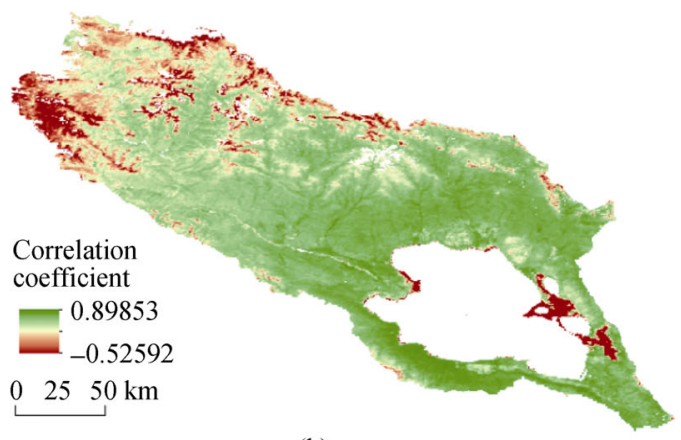

(b)

Figure 8 Correlations between monthly EVI and climate factors of current month in the Qinghai Lake Basin during 2001-2012 (a. with annual precipitation; b. with annual mean temperature)

\subsubsection{Lag effect of vegetation dynamics}

Lag effect is thought to be common features of vegetation ecosystems. Prior studies indicated that maximum photosynthetic activity is linked with precipitation in the current and preceding months. For example, Li (2009) explores that there exists the time lag effect that NDVI responds to the rainfall and temperature changes in the Red River Basin. The range of the lag time is between 15 165 days. In order to analyze the lag effect of vegetation at inter-monthly time scale, correlation coefficient between EVI of current month and climate factors of previous month was calculated, and there was no obvious time-delay effect in the whole region. However, lag effects and cumulative effect of precipitation on vegetation coverage on a longer time scale had explored. Based on correlation coefficient between autumn precipitation from 2001 to 2011 and the next spring EVI value from 2002 to 2012, totally, the autumn precipitation has a strong correlation with the next spring EVI values in the whole region. The area percentage of the regions where EVI value showed positive correlation with precipitation was over $99 \%$, and $92.68 \%$ area has an extremely significant positive correlation (Figure 9). This finding indicated the autumn precipitation was the dominant

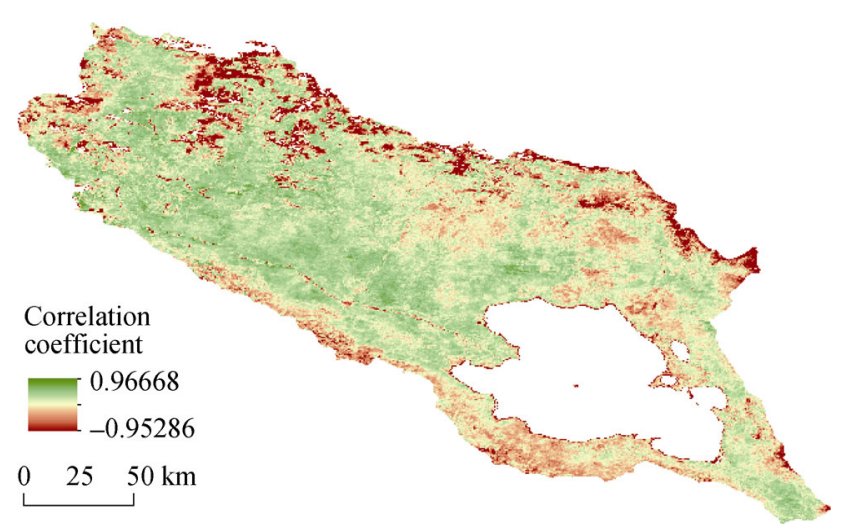

Figure 9 Correlations between autumn precipitation and next spring EVI value from 2001 to 2012 driving factor that limited the plant growth of next spring. This suggests that soil moisture plays an important and immediate role in vegetation response to precipitation, and in the QLB region, vegetation biomass varied greatly with the change of soil water availability due to inter-annual variability in precipitation (Holben, 1986; Breshears and Barnes, 1999; Loik et al., 2004; McCulley et al., 2005). 


\section{Discussion and conclusions}

Global warming has led to significant vegetation changes in recent years. The Qinghai-Tibet Plateau has been suggested to be susceptible to future climate change. Climate change probably played a major role in such a trend of vegetation growth variation. However, assessing the causes and consequence of these spatio-temporal patterns will require new monitoring and analysis tools. This study illustrates that the MODIS time series dataset provides great potential for monitoring indicators of environmental change and ecosystem health. In this paper, we focus on the integration and application of multi-methods and spatial analysis techniques in GIS to study the multi-temporal fluctuations of vegetation EVI value in the QLB, analyze its responses to climate change, and map the spatial pattern changes of EVI by using MODIS time-series data and meteorological data of temperature and precipitation from 2001 to 2012. The following conclusions can be drawn.

(1) Temporal pattern

EVI changing trend line revealed that the overall vegetation EVI of the QLB increased $6 \%$ during recent 12 years. The EVI value in growing seasons including spring and summer exhibited very significant improving trend, accounted for $12.8 \%$ and $9.3 \%$ respectively. These indicated the phonology of steppe grassland in the QLB had changed, namely, the date of turning green advanced, and the length of growing season increased. The results are in agreement with some previous studies, which indicated an increase in EVI during the growing season resulted from both the advanced growing season and accelerated vegetation activity. To some extent the results also reflect the feedback mechanisms of vegetation to global warming in the high-cold mountain area of northern Hemisphere.

(2) Spatial heterogeneity

Generally, the spatial pattern of the 12-year mean EVI showed obvious spatial heterogeneity. Ecosystem types distributed most widely in the regions were alpine meadow, alpine steppe, and temperate montane meadow. Above vegetation types varied along the altitudinal gradient. The difference in vegetation types exerted important effects on EVI pattern. Overall, the vegetation coverage improved in most parts, while degraded slightly in a small part only. For the whole region, the area where the EVI value showed an increasing trend accounted for $77.9 \%$, and about $5 \%$ area had a very significant increase. The increased areas were mainly distributed in south of the Qinghai Lake shore (montane shrub-steppe zone), central temperate meadow steppe zone of north of the Qinghai Lake, and the Buha river bank shrub-steppe zone; the area with EVI decreased was $22.1 \%$, which sporadically distributed in the western and northern parts of montane steppe zone, eastern lake shore desert-steppe and desert zone. The reason might be that the above regions with relative low precipitation, high temperature tended to strengthen the evaporation, reducing the available water content, and then, limiting plant growth, and under this condition, vegetation coverage, consequently, exhibited negative correlation with temperature.

(3) Response mechanism at different time scales

Vegetation coverage change was closely correlated with climatic factors, and annual and seasonal climate changes can bring various influences on vegetation growth. Generally speaking, in the QLB, precipitation was the dominant driving factor for vegetation growth; however, at different time scales its weight to vegetation varied. 
At inter-annual scale, the correlation coefficient between EVI and precipitation was 0.23 , while that of EVI and temperature was 0.098. The area where EVI (vegetation coverage) was positively correlated with precipitation and temperature accounted for $77.44 \%$ and $64.12 \%$ of the whole region, respectively. Annual average of vegetation change was better correlated with precipitation, suggesting that rainfall was the main factor driving vegetation change.

The growing season of the QLB is from May to September according to the hydrothermal condition. The EVI correlated with precipitation and temperature accounted for 0.27 and 0.28 respectively. It can be concluded that vegetation coverage was sensitive to both precipitation and temperature, or rather to suitable combination of the two.

Vegetation EVI displayed a strong positive correlation with precipitation (0.87) and temperature (0.77) at inter-monthly scale. Correlation between EVI and monthly precipitation was far robust than that between EVI and mean monthly temperature, showed precipitation was a more important factor determining vegetation growth by contrast with temperature. Moreover, relationships between monthly variation of EVI and climatic factors represent temporal rhythm controls of temperature and precipitation on vegetation growth, and to some extent, it might be the strategy for alpine vegetation in the QLB.

Based on geo-statistical analysis, the autumn precipitation has a strong correlation with the next spring EVI values in the whole region. This findings explore the autumn precipitation is an important indicator, and then, limits the plant growth of next spring.

\section{References}

Anderson R G, Canadell, J G, Randerson J T et al., 2010. Biophysical considerations in forestry for climate protection. Frontiers in Ecology and the Environment, 9(3): 174-182.

Breshears D D and Barnes F J, 1999. Interrelationships between plant functional types and soil moisture heterogeneity for semiarid landscapes within the grassland/forest continuum: A unified conceptual model. Landscape Ecology, 14(5): 465-478.

Carpenter C, 2005. The environmental control of plant species density on a Himalayan elevation gradient. Journal of Biogeography, 32(6): 999-1018.

Chamaille-Jammes S, Fritz H, Murindagomo F, 2006. Spatial patterns of the NDVI-rainfall relationship at the seasonal and inter-annual time scales in an African savanna. International Journal of Remote Sensing, 27(23): 5185-5200.

Chen J, Jonsson P, Tamura M et al., 2004. A simple method for reconstructing a high-quality NDVI time-series dataset based on the Savitzky-Golay filter. Remote Sensing of Environment, 91: 332-344.

Chen X, Hu B, Yu R, 2005. Spatial and temporal variation of phonological growing season and climate change impacts in temperate eastern China. Global Change Biology, 11: 1118-1130.

Chen Xiaoguang, Li Jianping, Li Zhijun et al., 2007. Vegetation coverage and its relation with climate change in Qinghai Lake area. Journal of Desert Research, 27(5): 797-804. (in Chinese)

Cramer W, Bondeau A, Woodward F I et al., 2001. Global response of terrestrial ecosystem structure and function to $\mathrm{CO}_{2}$ and climate change: Results from six dynamic global vegetation models. Global Change Biology, 7: 357-373.

Fay P A, Kaufman D M, Nippert J B et al., 2008. Changes in grassland ecosystem function due to extreme rainfall events: Implications for responses to climate change. Global Change Biology, 14: 1600-1608.

Feng S, Tang M C, Wang D M, 1998. New evidence for the Qinghai-Xizang (Tibet) Plateau as a pilot region of climatic fluctuation in China. Chinese Science Bulletin, 43(20): 1475-1479.

Frolking S, Palace M W, Clark D B et al., 2009. Forest disturbance and recovery: A general review in the context of spaceborne remote sensing of impacts on above-ground biomass and canopy structure. Journal Geophysical Research, 114.

Gao X, Huete A R, Ni W G et al., 2000. Optical-biophysical relationships of vegetation spectra without background contamination. Remote Sensing of Environment, 74: 609-620.

Gaston K J, 2000. Global patterns in biodiversity, Nature, 405(6783): 220-227.

Guillevic P, Koster R D, Suarez M J et al., 2002. Influence of the inter-annual variability of vegetation on the 
surface energy balance: A global sensitivity study. Journal of Hydrometeorology, 3(6): 617-629.

Holben B N, 1986. Characteristics of maximum value composite images from temporal AVHRR. International Journal of Remote Sensing, 7: 1417-1434.

Huete A R, Didan K, Miura T et al., 2002. Overview of the radiometric and biophysical performance of the MODIS vegetation indices. Remote Sensing of Environment, 83(1/2): 195-213.

Huete A R, Justice C, Liu H, 1994. Development of vegetation and soil indexes for MODIS-EOS. Remote Sensing of Environment, 49: 224-234.

Huete A R, Liu H Q, Batchily K et al., 1997. A comparison of vegetation indices global set of TM images for EOS-MODIS. Remote Sensing of Environment, 59(3): 440-451.

Jackson R B, Randerson J T, Canadell J G et al., 2008. Protecting climate with forests. Environmental Research Letters, 3, 044006.

Justice C, Vermote E, Townshend J et al., 1998. The Moderate Resolution Imaging Spectroradiometer (MODIS): Land remote sensing for global change research. IEEE Transactions on Geoscience and Remote Sensing, 36, 1228-1249.

Li Yungang, He Daming 2009. The spatial and temporal variation of NDVI and its relationships to the climatic factors in Red River Basin. Journal of Mountain Science, 27(3): 333-340.

Li D, Lewis J, Rowland J et al., 2004. Evaluation of land performance in Senegal using multi-temporal NDVI and rainfall series. Journal of Arid Environments, 59(3): 463-480.

Loik M E, Breshears D D, Lauenroth W K et al., 2004. A multi-scale perspective of water pulses in dryland ecosystems: climatology and ecohydrology of the western USA. Oecologia, 141(2): 269-281.

Mao F, Tang S H, Sun H et al., 2008. A study of dynamic change of dry and wet climate regions in the Tibetan Plateau over the last 46 years. Chin. J. Atmos. Sci., 32: 499-507. (in Chinese)

McCulley R L, Burke I C, Nelson J A et al., 2005. Regional patterns in carbon cycling across the Great Plains of North America. Ecosystems, 8: 106-121.

$\mathrm{Mu}$ Shaojie, Yang Hongfei, Li Jianlong et al., 2013. Spatio-temporal dynamics of vegetation coverage and its relationship with climate factors in Inner Mongolia, China. Journal of Geographical Science, 23(2): 231-246.

Nemani R, Hashimoto H, Votava P et al., 2009. Monitoring and forecasting protected area ecosystem dynamics using the Terrestrial Observation and Prediction System (TOPS). Remote Sensing of Environment, 113, 1497-1509.

Nemani R R, Keeling C D, Hashimoto H et al., 2003. Climate-driven increases in global terrestrial net primary production from 1982 to 1999 . Science, 300(5625): 1560-1563.

Piao S, Friedlingstein P, Ciais P et al., 2007. Growing season extension and its impact on terrestrial carbon cycle in the Northern Hemisphere over the past 2 decades. Global Biogeochemical Cycles, 21(3): GB3018.

Piao S L, Cui M D, Chen A P et al., 2011. Altitude and temperature dependence of change in the spring vegetation green-up date from 1982 to 2006 in the Qinghai-Xizang Plateau. Agricultural and Forest Meteorology, 151, 1599-1608.

Piao S L, Fang J Y, Ji W et al., 2004. Variation in a satellite-based vegetation index in relation to climate in China. Journal of Vegetation Science, 15(2): 219-226.

Sims D A, Rahman A F, Cordova V D et al., 2006. On the use of MODIS EVI to assess gross primary productivity of North American ecosystems, Journal of Geophysical Research, 111: G04015.

Theurillat J, Guisan A, 2001. Potential impact of climate change on vegetation in the European Alps: A Review. Climatic Change, 50: 77-109.

Verbesselt J, Hyndman R, Newnham G et al., 2010. Detecting trend and seasonal changes in satellite image time series. Remote Sensing of Environment, 114: 106-115.

Wang J, Rich P M, Price K P, 2003. Temporal responses of NDVI to precipitation and temperature in the central Great Plains, USA. International Journal of Remote Sensing, 24(11): 2345-2364.

Wang Junbang, Tao Jian, Li Guicai et al., 2010. Monitoring inter-annual vegetation variation in middle Inner Mongolia through MODIS NDVI. Journal of Geo-information Science, 12(6): 835-842.

White A B, Kumar P, Tcheng D, 2005. A data mining approach for understanding topographic control on climate-induced inter-annual vegetation variability over the United States, Remote Sensing of Environment, 98: $1-20$.

$\mathrm{Xu}$ Jianhua, 2002. Mathematical Methods in Contemporary Geography. Beijing: High Education Press. (in Chinese)

$\mathrm{Xu}$ X Q, Chen H, LEVY Jason K, 2008. Plateau vegetation cover change and its spatial and temporal characteristics of the Causes of climate warming. Chinese Science Bulletin, 54(3): 456-462.

Zhang Geli, Xu Xingliang, Zhou Caiping et al., 2011. Responses of grassland vegetation to climatic variations on different temporal scales in Hulun Buir Grassland in the past 30 years. Journal of Geographical Sciences, 21(4): 634-650.

Zhou L, Tucker C J, Kaufmann R K et al., 2001. Variations in northern vegetation activity inferred from satellite data of vegetation index during 1981 to 1999. Journal of Geophysical Research, 106(D17): 20069-20083. 